Pesq. Vet. Bras. 30(4):295-300, abril 2010

\title{
Estrutura e celularidade de meniscos frescos de coelhos (Oryctolagus cuniculus) preservados em glicerina ${ }^{1}$
}

\author{
Liana M. Vilela², Ricardo J. Del Carlo ${ }^{3}$, João Carlos P. da Silva ${ }^{4}$, Sérgio Luís \\ P. Da Matta ${ }^{5}$, Mauricio Correia D. Rodrigues ${ }^{2}$, Betânia S. Monteiro², Mastoby \\ Miguel M. Martinez ${ }^{2}$, Amanda Maria S. Reis ${ }^{6}$, Daniel P. Dias Machado ${ }^{6}$ e \\ Liliane R. Lopes ${ }^{6}$
}

\begin{abstract}
Vilela L.M., Del Carlo R.J., Silva J.C.P., Matta S.L.P., Rodrigues M.C.D., Monteiro B.S., Matinez M.M., Reis A.M.S., Machado D.P.D. \& Lopes L.R. 2010. [Structure and cellularity of the fresh menisci (Oryctolagus cuniculus) of rabbits and the menisci preserved in glycerin.] Estrutura e celularidade de meniscos frescos de coeIhos (Oryctolagus cuniculus) preservados em glicerina. Pesquisa Veterinária Brasileira 30(4):295-300. Departamento de Veterinária, Universidade Federal de Viçosa, 36570000 Viçosa, MG, Brazil. E-mail: ricarlo@ufv.br

In the present study was evaluated the tissue architecture, the percentage of cellular population, as well as viability and distribution of cells in fresh menisci of rabbits and preserved in $98 \%$ glycerin. Were analyzed medial menisci of rabbits freshly slaughtered, which were distributed into three groups: the MF group $(n=7)$, composed of fresh menisci, corresponded to the control group; the MG group $(n=7)$, composed by menisci preserved in $98 \%$ glycerin, for 30 days, and the MR group $(n=7)$ by menisci preserved in $98 \%$ glycerin and rehydrated in $\mathrm{NaCl} 0.9 \%$ for 12 hours. In all menisci were identified and quantified the different cell types: fibroblasts/fibrocytes and condrocytes. The cell population percentage was statistically similar in all groups. All menisci preserved in the MG and MR groups showed a lower intensity of color and shrinkage of collagen fibers, reduced volume and higher intensity of staining of nucleus (chromatin condensation), as compared to fresh menisci (MF), featuring the phenomenon of cell lysis. The cartilaginous matrix of preserved menisci proved to be well preserved because the tissue architecture was maintained. It was concluded that $98 \%$ glycerin is an optional preservation mean for meniscal allografts with a devitalized collagenous matrix.
\end{abstract}

INDEX TERMS: Articular cartilage, meniscal allograft, knee.

RESUMO.- No presente estudo foi avaliada a arquitetura tecidual, a população celular, assim como a integridade e a distribuição dos tipos celulares em meniscos frescos de coelhos e preservados em glicerina $98 \%$. Foram analisados meniscos mediais de coelhos recém abatidos, que

\footnotetext{
${ }^{1}$ Recebido em 29 de dezembro de 2008.

Aceito para publicação em 11 de agosto de 2009.

2 Pós-graduando em Medicina Veterinária, Universidade Federal de Viçosa (UFV), Viçosa, MG 36570-000, Brasil.

${ }^{3}$ Departamento de Veterinária (DVT), UFV, Viçosa, MG. *Autor para correspondência: ricarlo@ufv.br

${ }^{4}$ Setor de Patologia, DVT, UFV, Viçosa, MG.

${ }^{5}$ Departamento de Biologia Geral, UFV, Viçosa, MG.

${ }^{6}$ Graduando, DVT, UFV, Viçosa, MG.
}

foram distribuídos em três grupos: o grupo MF ( $n=7)$, composto por meniscos frescos, correspondeu ao grupo controle; o grupo MG ( $n=7)$, composto por meniscos preservados em glicerina $98 \%$, por 30 dias, e o grupo MR $(n=7)$, por meniscos preservados em glicerina $98 \%$ e reidratados em $\mathrm{NaCl} 0,9 \%$, por 12 horas. Em todos os meniscos foram identificados e quantificados os diferentes tipos celulares: fibroblastos/fibrócitos e condrócitos. A população celular foi estatisticamente semelhante nos três grupos de meniscos, sendo que os meniscos preservados, grupos MG e MR, apresentaram menor intensidade de coloração e retração das fibras colágenas, diminuição de volume e maior intensidade de coloração dos núcleos (condensação da cromatina), em relação aos meniscos frescos (MF), caracterizando o fenômeno de lise celular. 
A matriz fibrocartilaginosa dos meniscos preservados revelou-se bem preservada mantendo a arquitetura tecidual dos meniscos. Conclui-se que a glicerina $98 \%$ é uma opção de meio de preservação para meniscos objetivando aloenxerto, com matriz colágena desvitalizada.

TERMOS DE INDEXAÇÃO: Cartilagem articular, aloenxerto meniscal, joelho.

\section{INTRODUÇÃO}

Os meniscos são estruturas fibrocartilaginosas semilunares interpostas entre as superfícies articulares do fêmur e da tíbia, de vital importância para a boa função e preservação da articulação do joelho (Barret et al. 1998). Os condrócitos são as células predominantes nos meniscos e se apresentam em maior quantidade nos cornos desses, envolvidos por abundante substância intersticial. Os fibrócitos são encontrados principalmente na metade externa do menisco, distribuídos entre os feixes de fibras colágenas (Somer \& Somer 1983).

A meniscectomia total e a substituição dos meniscos por aloenxertos são procedimentos freqüentemente realizados quando outras opções para reparo ou reconstrução do menisco não puderem ser utilizadas (Rijk 2004, Reckers et al. 2005), e tem como objetivo evitar as alterações degenerativas nas cartilagens articulares (Cury et al. 2002). A substituição por aloenxerto, no caso a fibrocartilagem de menisco, apresenta como vantagem a possibilidade de utilizar um tecido semelhante, em sua morfologia, ao tecido que está sendo substituído (Reckers et al. 2005). As desvantagens estão na dificuldade de técnica de preservação, na possibilidade do enxerto ser vetor de doenças infecto-contagiosas, nos eventuais processos de reações imunológicas e na viabilidade do enxerto (Buma et al. 2004, Reckers et al. 2005, Torres et al. 2006).

Não há na literatura consenso sobre a influência da celularidade do menisco transplantado, conseqüência direta da técnica de preservação. Alguns autores preconizam que a viabilidade celular é um fator de melhor integração, enquanto outros dão preferência ao transplante de uma matriz de colágeno desvitalizada (Reckers et al. 2005). A refrigeração a $4^{\circ} \mathrm{C}$ preserva a viabilidade celular, sem alterar a arquitetura do menisco (Felix \& Paulos 2003, Reckers et al. 2005). Vários estudos têm sugerido que uma população viável de condrócitos pode ter efeito benéfico na manutenção da matriz extracelular e na integridade mecânica do enxerto após o transplante (Rijk 2004). O obstáculo a este procedimento é coordenar o período em que as células mantêm-se viáveis (Felix \& Paulos 2003).

$\mathrm{O}$ congelamento em temperaturas a partir de $70^{\circ} \mathrm{C}$ negativos é o método mais amplamente utilizado para preservação de meniscos, ocasionando a morte de todas as células, porém mantendo a arquitetura tecidual (Reckers et al. 2005). Trata-se de um processo pouco oneroso e apesar da total lise celular, tem demonstrado resultados clínicos satisfatórios (Aagaard et al. 1999, Cury et al. 2002). O congelamento em temperaturas inferiores a $0^{\circ} \mathrm{C}$ mantém a viabilidade celular por até cinco dias (Cury et al. 2002, Reckers et al. 2005).

A criopreservação mantém, pelo menos parcialmente, a integridade da membrana celular e a viabilidade de condrócitos do doador (Verdonk \& Kohn 1999, Rijk 2004). Este método mantém entre 30 e $40 \%$ de células viáveis, mas esta porcentagem diminui com o tempo de estocagem (Rijk 2004). DeBeer et at. (2000) encontraram que 95\% das células do doador haviam sido substituídas, um ano após o implante, por células do hospedeiro em um enxerto criopreservado de menisco humano. O papel da viabilidade celular nos transplantes de menisco não é claro no momento (Rijk 2004).

$\mathrm{Na}$ liofilização ou congelamento a seco ocorre completa inviabilidade celular (Cury et al. 2002, Wirth et al. 2002, Felix \& Paulos 2003). Os autores partidários de que somente a matriz desvitalizada do menisco já é suficiente para o sucesso do transplante, preconizam seu uso (Felix \& Paulos 2003, Rijk 2004, Reckers et al. 2005).

A glicerina a $98 \%$, mantida em temperatura ambiente, apresenta como vantagens o baixo custo e a propriedade antisséptica, atuando como bactericida e fungicida, além de reduzir a antigenicidade do tecido nela conservado, preservar a textura do tecido e aumentar a resistência à tração, sem alterar o grau de elasticidade (Pigossi 1967). Krauspenhar (2003) recomendou que o período mínimo para preservação dos enxertos é de 30 dias, pois a eliminação de bactérias gram negativas pode requerer até 27 dias.

O objetivo desse estudo foi identificar e avaliar a arquitetura tecidual, os tipos celulares presentes, assim como analisar a distribuição e a integridade das células de meniscos frescos de coelhos, meniscos preservados em glicerina $98 \%$ por 30 dias e meniscos preservados em glicerina $98 \%$ por 30 dias, seguido de reidratação em solução salina por 12 horas, por meio de análises in vitro, no intuito de estabelecer um banco de tecidos para futuros aloenxertos meniscais.

\section{MATERIAL E MÉTODOS}

A metodologia adotada durante o desenvolvimento deste trabalho foi aprovada pela comissão de Ética do Departamento de Veterinária, da Universidade Federal de Viçosa (UFV), sob parecer $n^{\circ}$ 89/2007.

Foram utilizados meniscos mediais $(n=21)$ de 11 coelhos albinos da raça Nova Zelândia, com idade entre três e quatro meses e peso médio de $3 \mathrm{~kg}$, oriundos de criação comercial da cunicultura do Departamento de Zootecnia da UFV. A retirada dos meniscos foi realizada imediatamente após o abate e em condições de limpeza, mas sem rigores de assepsia.

Uma incisão transversal na cápsula articular envolvendo o ligamento colateral medial foi realizada e um esforço em valgo foi o suficiente para facilitar a visualização e o acesso ao menisco medial. Foram seccionados os ligamentos cruzado cranial e caudal, meniscotibial cranial e caudal, meniscocapsulares e o intermeniscal, e realizada a coleta dos meniscos (Fig.1A e 1B). Os restos de ligamentos e tecido adiposo aderidos foram 

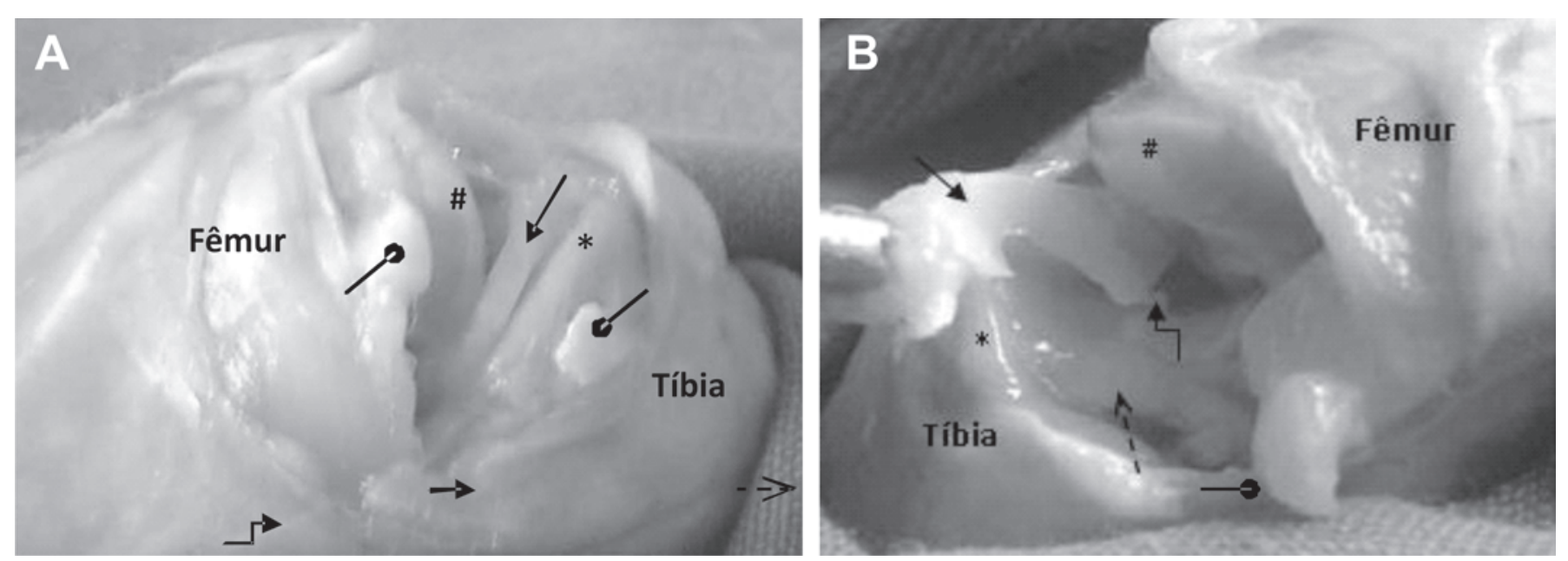

Fig.1. Procedimento de coleta dos meniscos mediais de coelhos. (A) incisão transversal da cápsula articular, articulação exposta e ligamento colateral medial seccionado. (B) Após secção dos ligamentos cruzados, meniscocapsulares, meniscotibial cranial e intermeniscal, o menisco se encontra fixo pelo ligamento meniscotibial caudal. (menisco medial; ligamento cruzado cranial; ligamento colateral medial; ligamento meniscotibial do corno caudal; \# côndilo femoral; * platô tibial).

removidos e os meniscos mediais coletados foram acondicionados em frascos individuais de vidro e distribuídos aleatoriamente em três grupos, com sete meniscos cada. O grupo MF foi composto por meniscos frescos (recém-colhidos), e correspondeu ao grupo controle, estes meniscos foram imersos em formalina $10 \%$, tamponada, por 24 horas. O grupo MG foi composto por meniscos acondicionados na proporção glicerina $98 \% /$ menisco de 20:1, por 30 dias, em temperatura ambiente. Após esse período, os meniscos foram retirados da glicerina e imersos em formalina 10\% tamponada, por 24 horas. O grupo MR foi composto por meniscos que foram imersos em glicerina $98 \%$, por 30 dias, em temperatura ambiente. Logo após o período de preservação, os meniscos do grupo MR foram imersos em solução salina ( $\mathrm{NaCl}$ 0,9\%), durante 12 horas, para reidratação, simulando condições a que seriam submetidos nos períodos pré e trans-operatório. Em seguida, foram imersos em formalina $10 \%$ por 24 horas, para processamento histológico.

Os meniscos foram incluídos em parafina e seccionados em micrótomo rotativo a $5 \mu \mathrm{m}$ de espessura. Os cortes obtidos comportavam toda a extensão do menisco, sendo corados pelo método de hematoxilina e eosina (HE) (Grimaldi Filho 1981). Foram confeccionadas e analisadas duas lâminas de cada menisco totalizando 14 lâminas por grupo. Os meniscos foram divididos em três regiões para análise: corno-cranial, corpo e corno-caudal. A análise histométrica foi realizada pela contagem de 500 pontos aleatórios sobre cada região do menisco, registrando-se os pontos coincidentes sobre condrócitos e fibroblastos/fibrócitos, sendo os resultados expressos em percentual (\%), utilizando-se objetiva de 20x. Avaliou-se também a distribuição e a viabilidade celular nas três regiões, assim como a integridade da matriz extracelular fibrocartilaginosa (arquitetura tecidual).

As variáveis quantitativas foram submetidas aos testes de Normalidade (Lilliefors) e Homocedasticidade (Cochran) e, posteriormente, à análise de variância. Em caso de significância, foi realizado o teste de Duncan ou de Tuckey, conforme a instabilidade da variável. Quando não atendia às premissas de normalidade e homocedasticidade, foram realizadas as transformações apropriadas para posterior análise de variância (SAEG 1999).

\section{RESULTADOS E DISCUSSÃO}

A distribuição celular apresentou-se de forma semelhante nos três grupos estudados: MF, MG e MR. Em todos os grupos, os condrócitos foram as células predominantes, com maior presença nos cornos, onde se encontravam circundados por abundante substância intersticial (Fig.23). Já os fibrócitos, estavam presentes, principalmente, na metade externa do menisco, envolvidos por matriz conjuntiva (Fig.2-3), à semelhança do observado por Somer \& Somer (1983), em meniscos frescos de cães.

À microscopia, todos os fragmentos de meniscos dos grupos preservados em glicerina (MG) e preservados em glicerina e reidratados em $\mathrm{NaCl} 0,9 \%(\mathrm{MR})$ apresentaram sinais de gradativa desorganização celular (lise), caracterizada por maior condensação da cromatina nuclear e por crescente retração e perda da afinidade tintorial das fibras conjuntivas (Fig.3). Nesses grupos, a matriz fibrocartilaginosa revelou-se bem preservada mantendo a arquitetura tecidual.

A população celular (condrócitos e fibrócitos/fibroblastos) nos grupos de meniscos preservados (MG) e meniscos preservados e reidratados (MR) foi estatisticamente semelhante à densidade celular do grupo de meniscos frescos (MF), com valores médios percentuais de condrócitos $61,5,60,7$ e 60,5 e fibrócitos/fibroblastos $38,5,39,3$ e 39,5 para MF, MG e MR, respectivamente (Fig.4).

Neste trabalho, após preservação em glicerina $98 \%$, a integridade e conseqüentemente, a viabilidade celular não foram mantidas. De maneira diferente, Reckers et al. (2005) relataram que meniscos de coelhos congelados em diferentes temperaturas, por 30 dias, apresentaram um percentual de viabilidade celular de $30 \%$. Enquanto, Arnoczky et al. (1988), encontraram entre 30 e $40 \%$ de células viáveis em meniscos criopreservados de cães. $O$ comportamento diferente em relação à integridade celu- 

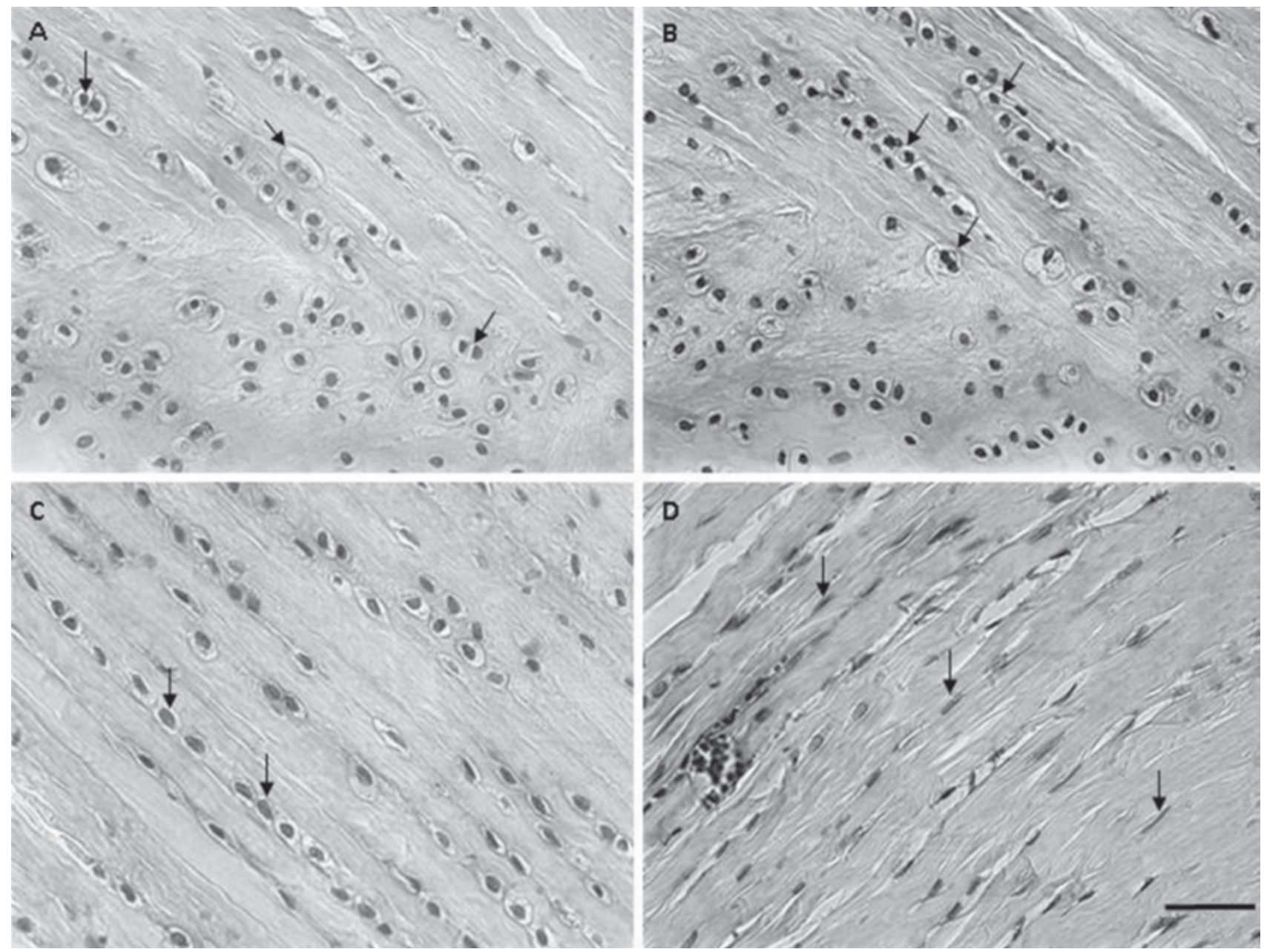

Fig.2. Fotomicrografias de meniscos do grupo MF - meniscos frescos. (A,B) Campo microscópico contendo condrócitos ( $\rightarrow$ ), circundados por abundante substância intersticial, nos cornos meniscais; (C,D), campo microscópico contendo fibrócitos/fibroblastos $(\rightarrow)$ envolvidos por matriz conjuntiva, no corpo do menisco. HE. Barra $=10 \mu \mathrm{m}$.

lar pode ser explicado pelos estudos realizados por Verdonk \& Kohn (1999), quando demonstraram que a criopreservação preserva parcialmente a integridade da membrana celular e a viabilidade de condrócitos.

A glicerina $98 \%$ não foi capaz de manter a integridade celular e impedir a desorganização progressiva dos constituintes celulares dos meniscos nela preservados, não mantendo assim as células viáveis. Já o congelamento, como utilizado por Arnoczky et al. (1988), Verdonk \& Kohn (1999) e Reckers et al. (2005), determinou a diminuição do metabolismo celular em níveis capazes de preservar a viabilidade. Estes mesmos autores (Reckers et al. 2005) também concluíram que dependendo do método de congelamento utilizado, a celularidade diminui de modo diferente, sendo a quantidade de células viáveis menor nas temperaturas mais baixas.

A glicerina $98 \%$ não causou alterações significativas na integridade morfológica e estrutural do menisco. Após a reidratação em $\mathrm{NaCl}$ 0,9\%, grupo MR, que foi realizada conforme recomendação de Costa (1996) e Del Carlo et al. (1999), a arquitetura tecidual foi mantida, à seme-
Ihança do observado no grupo de meniscos preserva$\operatorname{dos}(M G)$.

Os meniscos contém cerca de $75 \%$ de água, $20 \%$ de fibras colágenas, além de glicosaminoglicanos, células e pequena quantidade de fibras elásticas (Buma et al. 2004). Como após a preservação em glicerina $98 \%$ e reidratação, o padrão morfológico se manteve em relação aos meniscos frescos, recém coletados, admite-se que a glicerina preservou, ainda que parcialmente a arquitetura tecidual e presumivelmente suas propriedades mecânicas.

Apesar de Rijk (2004) preconizar o transplante de meniscos com células viáveis, a glicerina $98 \%$ passa a ser uma opção de meio de preservação, para os autores que preconizam o transplante de menisco, como uma matriz colágena desvitalizada (Aagaard et al. 1999, Cury et al. 2002), à semelhança dos enxertos que são congelados a partir de $70^{\circ} \mathrm{C}$ negativos, onde ocorre a lise de todas as células com manutenção da arquitetura tecidual (Verdonk \& Kohn 1999, Reckers et al. 2005). Também, questiona-se a necessidade de viabilidade celular no momento do trans- 


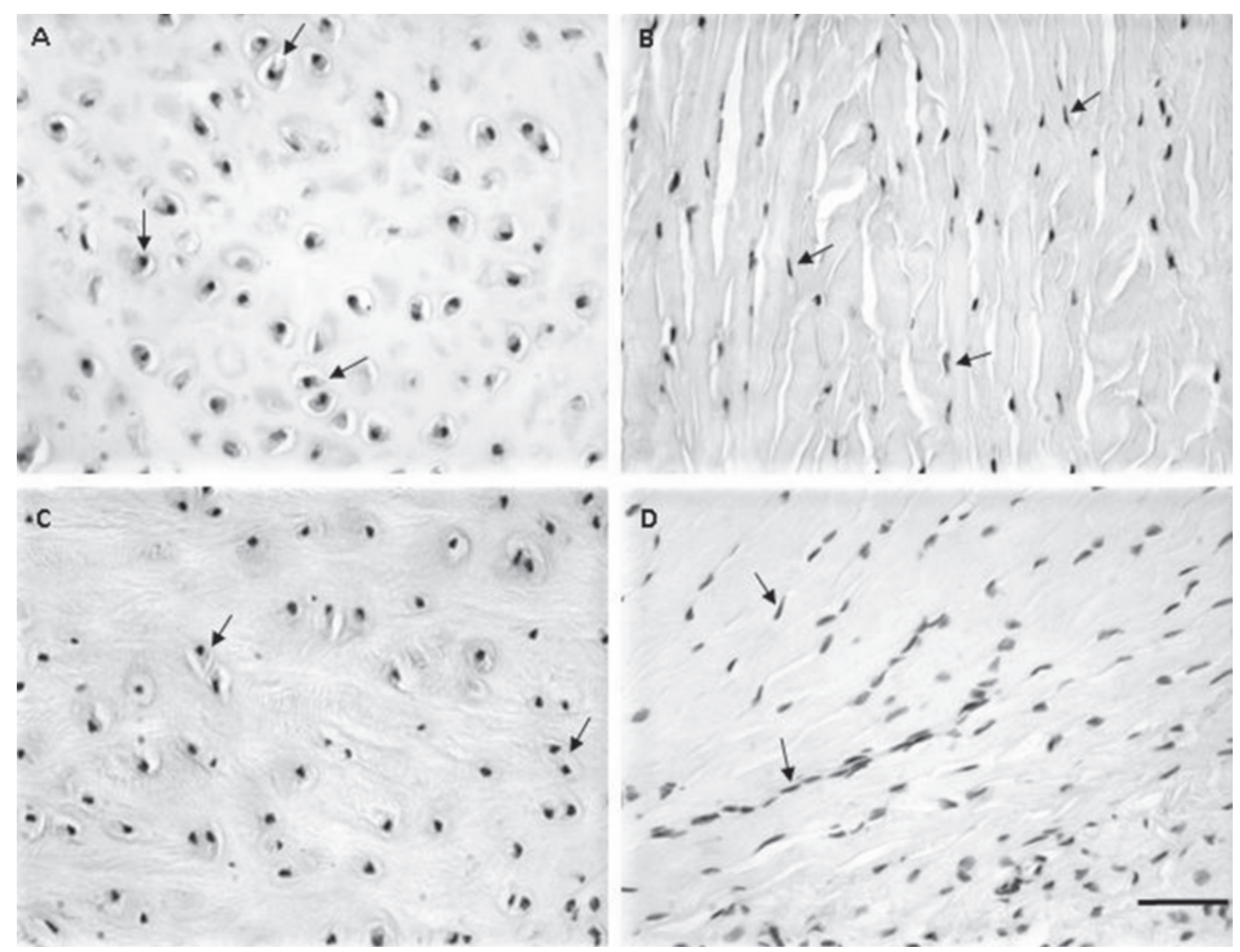

Fig.3. (A,B) Meniscos do grupo MG, preservados em glicerina $98 \%$ por 30 dias. (C,D) Meniscos do grupo MR, preservados em glicerina $98 \%$ por 30 dias e reidratados em NaCl $0,9 \%$ por 12 horas. $(\mathbf{A}, \mathbf{C})$ Condrócitos $(\rightarrow)$ circundados por abundante substância intersticial, presentes nos cornos meniscais. (B,D) Fibrócitos/fibroblastos $(\rightarrow)$ envolvidos por matriz conjuntiva. Observam-se sinais de lise celular nesses dois grupos (alterações dos núcleos pela redução da cromatina), perda da coloração geral e retração das fibras colágenas. HE. Barra $=10 \mu \mathrm{m}$.

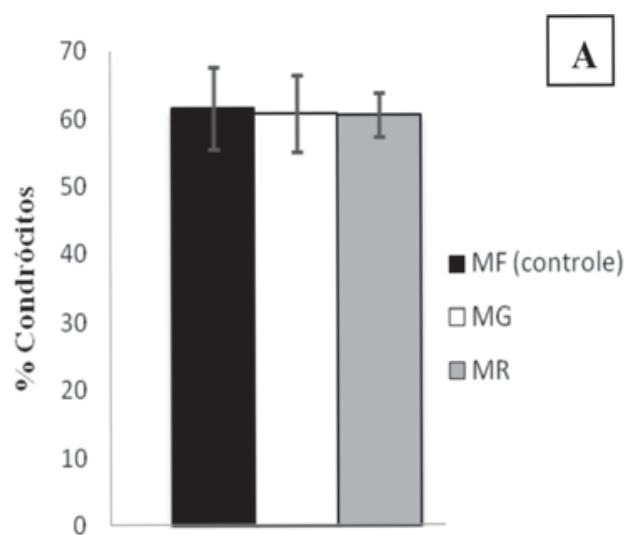

Grupos

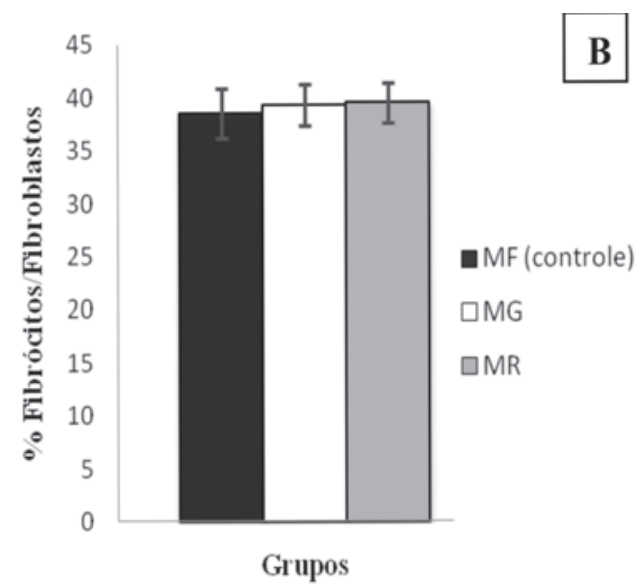

Fig.4. (A) Representação dos valores médios percentuais de condrócitos e (B) fibrócitos/ fibroblastos observados nos três grupos: meniscos frescos (MF), meniscos preservados em glicerina (MG) e meniscos preservados em glicerina e reidratados (MR). Os tratamentos não diferem entre si ao nível de $5 \%$ de probabilidade. 
plante, já que de DeBeer et al. (2000) observaram que 95\% das células do doador, haviam sido substituídas por células do hospedeiro, em um enxerto criopreservado de menisco humano, um ano após a cirurgia.

\section{CONCLUSÃO}

Conclui-se que a glicerina $98 \%$ preservou a arquitetura tecidual dos meniscos, podendo ser uma opção de meio de preservação de aloenxertos meniscais, para utilização em transplantes de meniscos, com matriz colágena desvitalizada.

\section{REFERÊNCIAS}

Aagaard H., Jörgensen U. \& Bojsen-Möller F. 1999. Reduced degenerative articular cartilage changes after meniscal allograft transplantation in sheep. Knee Surg. Sports Traumatol. Arthroscopy 7:184-191.

Arnoczky S.P., McDevitt C.A., Schmidt M.B., Mow V.C. \& Warren R.F. 1988. The effect of cryopreservation in canine menisci: A biomechanical and morphologic evaluation. J. Orthopaed. Res. 6:1-12.

Barret G.R., Field M.H., Treacy S.H. \& Ruff C.G. 1998. Clinical results of meniscus repair in patients 40 years and older. Arthroscopy 14:824829.

Buma P., Ramrattan N.N., Van Tienen T.G. \& Veth R.P.H. 2004. Tissue engineering of the meniscus. Biomaterials 25(9):1523-1532.

Costa J.L.O. 1996. Reconstrução de grande falha óssea com enxerto cortical alógeno conservado em glicerina, fixado com placa e parafusos de aço inoxidável da série 304: estudo experimental em cães (Canis familiaris). Dissertação de Mestrado, Universidade Estadual de São Paulo, Campus de Jaboticabal, SP. 100p.

Cury R.P.L., Camargo O.P.A., Próspero J.D., Botter F.C.S., Severino N.R., Aihara T. \& Oliveira V.M. 2002. Transplante Homólogo de menisco: estudo experimental em coelhos. Revta. Bras. Ortoped. Traumatol. 37(8):341-350.
DeBeer P., Decorte R. \& Bellemans J. 2000. DNA analysis of a transplanted cryopreserved meniscal allograft. Arthroscopy 16:71-75.

Del Carlo R.J., Galvão S.R., Viloria M.I.V., Souza T.D. \& Filho A.M. 1999. Aloenxertos ósseos caninos diferentemente preservados. Revta Bras. Ciênc. Vet. 6(3):121-126.

Felix N.A. \& Paulos L.E. 2003. Current status of meniscal transplantation. Knee 10:13-17.

Grimaldi Filho G. 1981. Manual de Técnica Histológica. Instituto Oswaldo Cruz, Rio de Janeiro. 287p.

Krauspenhar L.C. 2003. Viabilidade bacteriana no Meio de conservação glicerina $98 \%$ do tendão calcâneo comum. Dissertação de Mestrado em Cirurgia Veterinária, UFSM, Santa Maria, RS. 62p.

Pigossi N. 1967. Glicerina na conservação de dura-máter. Estudo experimental. Dissertação de Livre Docência, Universidade de São Paulo, São Paulo, SP.

Reckers L.J., Fagundes D.J., Cohen M., Raymundo J.L.P., Moreira M.B. \& Paiva V.C. 2005. Effects of different preservation temperatures and periods menisci cellularity in rabbits. Acta Cirurgica Bras. 20(6):428432.

Rijk P.C. 2004. Meniscal allograft transplantation. Part I. Background, results, graft selection and preservation, and surgical considerations. Arthroscopy 20(7):728-743.

SAEG 1999. Sistema para análises estatísticas e genéticas. Versão 8.1. Fundação Arthur Bernardes, Universidade Federal de Viçosa, Viçosa, MG.

Somer L. \& Somer T. 1983. Is the meniscus of the knee joint a fibrocartilage? Acta Anatomica 116(3):234-244.

Torres B.B.J., Muzzi L.A.L., Muzzi R.A.L. \& Valério A.G. 2006. Como proceder nas lesões meniscais em cães: revisão. Clín. Vet. (63):4858.

Verdonk R. \& Kohn D. 1999. Harvest and conservation of meniscal allografts. Scand. J. Med. Sci. Sports 9:158-159.

Wirth C.J., Peters G., Milachowski K.A., Weismeier K.G. \& Kohn D. 2002. Long-term results of meniscal allograft transplantation. Am. J. Sports Med. 30:174-181. 